ISSN 1991- 8690

website:http:// jsci.utq.edu.iq
الترقيم الدولي 8690 - 2 - 2091

Email: utjsci@utq.edu.iq

\title{
Comparison of plasma lipid peroxidation between migraine and tension type headache in Iraqi patients.
}

\author{
Suaad Muhammed Abd - Alqader \\ College of Pharmacy-University of Basrah -Basrah -IRAQ \\ Email: msbb2097@gmail.com
}

\begin{abstract}
The oxidant-antioxidant balance disorders underlie a number of acute and chronic diseases of the central nervous system (CNS). It is believed that oxidative stress plays a role in the pathogenesis of migraine. The study objective is to assess the processes of lipid peroxidation with malondialdehyde (MDA) as its major indicator. The study was carried out on Iraqi patients to estimate the level of lipid peroxidation in three groups include control group (41subjects), tension-type headache (TTH) (41patients) and migraine (31patients). The migraine, TTH, and control groups were significantly different on the measures of MDA. The study showed that the migranieurs were significantly different from other two groups with respect to MDA $(\mathrm{p}<0.001)$. No significant difference between males and females within each of the three groups $(\mathrm{p}>0.05)$. The only significant difference between females' age-groups was reported between (15-27years) and (28-40years) years old-groups (according to Games-Howell test $(\mathrm{P}=0.013)$ while Tukey HSD and Dunnett test contradicted the exits of any differences between them $(\mathrm{P}>0.05)$. According to the major similarity between aged-groups for both males and females in the three groups, it can be concluded that MDA level is not affected by age.
\end{abstract}

Key words: Lipid peroxidation, malondialdehyde; oxidative stress; migraine, tension headache.

$$
\text { كلية الصيدلة - جامعة البصرة- البصرة- العراق }
$$

ان اختلالات الاتزان بين المؤكسدات - مضادات الاكسدة تتدرج تحت عدد من الامراض الحادة والمزمنة التي تصيب الجهاز العصبي

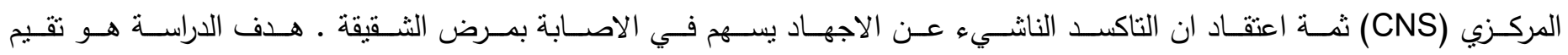

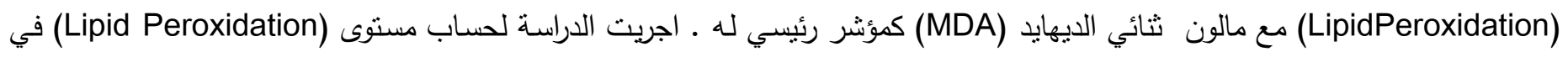
ثلاث مجاميع تثمل المجموعة القياسية (Control) . 31 (Migraine) 
تباينت مجاميع الثقيقة ، الصداع الثوتري والمجموعة القياسية بفارق ذي معنى في مقياس (MDA). حيث ان قيهة الـ (MDA) الأعلى لوحظت بين مرضى الثقيقة. أظهرت الدراسة ان مرضى الثقيقة كانو مختلفين بشكل معنوي عن المجموعتين الاخريتين من حيث

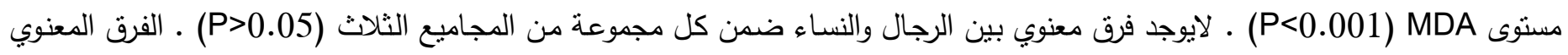
الوحيد تم تسجيله بين الفئتين العمرية (27- 15سنة) و (40 - 28سنة) بحسب اختبار

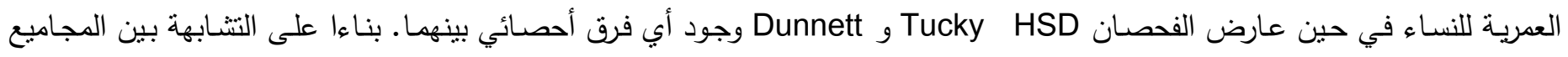
العمرية بالنسبة لكلا الرجال والنساء في الجاميع الثلاث ، يمكن الاستنتاج ان الـ MDA لايناثر بالعمر .

\section{Introduction}

Although migraine is a long-known disease, our understanding of its pathophysiology is a work in progress. The complexity of migraine pathogenesis suggests that an acute attack may be the final common expression of more than one type of initiating abnormalitys (1). Primary headaches example migraine and tension-type headache (TTH), associated with biochemical abnormalities of the brain.

Some of these aberrations predispose a person to headache, while others are pathophysiologically associated with the headache (2). Migraine headache is a public health problem of enormous scope that has an impact on the individual sufferer and on the society migraine typical characteristics of such headache are unilateral location, pulsating type, moderate or sever intensity association with nausea photophobia but tension type headache is more common in women. Tension type headache often interfere with the activities of daily living (3) (4).

We tried to investigate the alterations in lipid peroxidation marker malondialdehyde (MDA) via focusing on some aspects involved in migraine pathogenesis oxidative stress. The oxidantantioxidant balance is an important component of homeostasis in the organism. In physiological condition, very reactive products are constantly being formed in each aerobic organism. These products are referred to as reactive oxygen species, reactive nitrogen species or oxygen free radicals. At the same time, mechanisms of antioxidant defense are being trigged (5) (6). Malondialdehyde (M DA) is the most commonly marker that is used to investigate the presence of oxidative stress in biological system (7).

A high content of polyunsaturated fatty acids, particularly of arachidonic acid in the cellular membranes, increases the likelihood of peroxidation). It is believed that oxidative stress plays a certain role in the pathogenesis of epilepsy. A number of studies have been conducted on the processes of lipid peroxidation and the activities of antioxidant enzymes in epileptic children (8) (9) (10).

The aim of this study was to present the dereference values of oxidative stress parameters in migraine, tension- type headache compared clinically with healthy Iraqi control. Such information would allow us to make comparisons between normal and abnormal states and provide a better understanding in diseases accompanied by oxidative stress.

\section{Material \&Method}

\section{Subjects}

The study includes three groups; 41 patients as control group; 20 males (17-48years), 21 females (18-50years), 41 patients with tensionheadache or TTH group; 21 males (18-55years), 19 females (19-51years), and 31patients as migraine groups; 16 males (17-45years), 15 females (2053years). Table (1) shows the general description of patients' gender and ages. There were no significant difference between males' and females' ages within each of the three groups $(\mathrm{P}>0.05)$. The medical histories for the patients were carefully 
checked for being clear from any infectious, malignant, and other serious disorders.

\section{Determination of Malondialdehyde}

Fasting venous blood ( $3 \mathrm{ml})$ was collected in a sterile EDTA vaccutainer at least 3days after the attack of headache the sample was centrifuged at 2000 r.p.m for 15 minutes. Determination plasma level of malondialdehyde (MDA) was preformed according to the procedure described by Shah SV et al. (11). For MDA measurement, (1ml) of $17.5 \%$ trichloroacetic acid was added to $(1 \mathrm{ml})$ of plasma and $(1 \mathrm{ml})$ of $0.6 \%$ thiobarbituric acid (TBA), then mixed and incubated in boiling water bath for 15 min then allowed to cool .After that $(1 \mathrm{ml})$ of $70 \%$ trichloroacetic acid (TCA) was added .Stand at room temp. for $20 \mathrm{~min}$ and the sample was centrifuged at 2000 r.p.m. for $15 \mathrm{~min}$. The supernatant was read spectophotometrically at 534 $\mathrm{nm}$.

\section{Statistical Analysis}

Levene test was applied to test for the equality of group variances. Levene test should be insignificant so as to ANOVA can be performed. The results of applying this test among all groups and subgroups showed that these comparisons were done for homogeneous groups (Sig.>0.05). Table (2) shows the descriptive statistical output resulted for MDA level in the control, TTH, and Migraine groups.

\section{Results}

The migraine, TTH, and control groups were significantly different on the measures of MDA. The highest values of MDA were observed among migraineurs [Figure 1]. The (Tukey HSD, Games Howell, and Dunnett tests) showed that migraineurs were significantly different from the other two groups with respect to MDA $(P<0.001)$. However, no significant difference was observed between the control group and the TTH group.

Within each main group there are male subgroup and female subgroup. Table (3) shows the statistical findings for three males' subgroups. Here also MDA shows the same behavior as that in the main group. It appears with the highest level also in male migraineurs $(\mathrm{P}>0.05)$ as obtained by (Tukey HSD, Games Howell, and Dunnett tests). With no significant difference between male subgroups in the other two groups.

Table (4) describes the main statistical features of females' subgroups. Again, Tukey HSD, Games Howell, and Dunnett tests manifest the similarity between MDA levels in control and TTH females with their significant difference from that of females' levels in migraine. Males and females were additionally divided by age into three groups 15-27, 28-40, and 41-53 years. Tables (5), (6), and (7) compare the MDA level in agegrouped males and females within control, TTH, and migraine samples respect.

t-test was performed to compare MDA levels between males and females of the same age group. No significant difference was found between them in control group for the three age periods; 1527years $(\mathrm{t}=0.240 ; \mathrm{P}=0.407), 28$-40years $(\mathrm{t}=0.811$; $\mathrm{P}=0.214)$, and 41-53years $(\mathrm{t}=0.500 ; \mathrm{P}=0.318)$.

Similarity was also manifested in the three age groups between males and females within TTH patients; $15-27$ years $\quad(\mathrm{t}=0.930 ; \quad \mathrm{P}=0.186), \quad 28$ 40years $(\mathrm{t}=-0.362 ; \mathrm{P}=0.361)$, and 41-53years $(\mathrm{t}=-$ $1.53 ; \mathrm{P}=0.088)$.

Statistical equality was also noticed when comparing the two genders of the same age group in migraineurs; $15-27$ years $(\mathrm{t}=0.758 ; \mathrm{P}=0.241), 28$ 40years $(\mathrm{t}=-1.26 ; \mathrm{P}=0.115)$, and $41-53$ years $(\mathrm{t}=-$ $0.136 ; \mathrm{P}=0.448)$.

\section{Discussion}

Lipid peroxidation is a free radical-related process, which potentially harmful because its uncontrolled, self-enhancing process causes disruption of membranes, lipid and other components. It has been found to be connected with various disease processes, such as carcinogenesis, arthrosclerosis and hypertension (12). Malondialdehyde (MDA) is a decomposition product of peroxidized polyunsaturated fatty acids that is widely preferred for detection of free oxygen radicals in various pathological conditions (13). 
MDA determined in the plasma was obtained from healthy volunteers control group, compared with migraine and tension type headache (TTH). Patients of the three groups were carefully checked for being clear from any infectious, malignant, and other serious disorders. This condition restricts the cause of raised MDA to the biochemical changes produced TTH or migraine only.

Our study shows increased MDA levels in plasma of migranieurs in comparison with tensiontype headache and control .Increased MDA levels in migraineurs reflect the increased lipid peroxidation .Lipid peroxidation in migraineurs occurs secondary to the oxidative stress .Migraineurs suffer from impaired brain energy phosphate metabolism during the initial stage of their $\operatorname{attack}(2)$ It is now believed that migraine is associated with in born predisposition to hypersensitive neurovascular reaction that may be induced by specific factors or may result from cyclic change in the CNS (14).

Findings of present study are similar to the previous studies $(15,16$, and 17) which reported that migraineurs suffer from higher levels of oxidative stress than control and TTH patients. The present study agrees also with Shimomura et al. (16), in that there is no significant difference in MDA levels between control and TTH patients. As mentioned before we have male subgroup within each main group. A significantly higher MDA can be seen in male migraineurs with respect to its levels in the other subgroups. Nilsen et al. (18) analyzed the effect of gender and environmental factors on MDA concentration in adults. They found a higher MDA concentration in plasma of women compared with men. Different results were shown by Diaz et al. (19); who did not find any differences in plasma activity of MDA, GSH-Px, NO and total antioxidant status between men and women.

Regarding females' subgroups; MDA showed the same behavior as that in males' subgroups. No significant difference between males and females subgroups can be resulted from applying independent sample t-test in each of the three main groups ( $\mathrm{p}>0.05)$.
Another comparison was done using ANOVA test to compare males in the age groups. Males-aged groups showed similarity within each of the three groups. While in females, the only significant difference was reported between (1527years) and (28-40years) groups according to Games-Howell test $(\mathrm{P}=0.013)$ while Tukey HSD and Dunnett test contradicted the exits of any differences between them. Since there were no significant differences between aged-groups for both males and females in the three groups, it can be concluded that MDA levels is not affected by age in control, TTH, and migraine groups. In addition, the similarity between MDA levels in males in comparison to that in females reveals that these levels are independent of gender.

There are a number of interpretation hypotheses to understand the pathophysiology of migraine and many attempts have been made to combine them all into one theory that would assume the involvement of brain vessels and trigeminal nerve (20). Recently it has been suggested that lipid peroxidation marker caused by free radicals may play role in migraine pathogenesis (21).

Among these, riboflavin, niacin, and coenzyme $\mathrm{Q}$ increase the substrate availability to complex I of the mitochondrial respiratory chain .The role played by mitochondrial is further supported by the evidence of therapeutic benefit shown by carnitine in migraineurs. Deficiency of carnitine palmityl transferase - II (CPT) - an enzyme that is used for the transportation of fatty acids inside mitochondri - induces migraine, with administration of carnitine (22). Furthermore, the blood level of pyruvic acid and lactic acid are higher in migraineurs than in controls and tensiontype headache subjects, thus providing direct evidence of mitochondrial dysfunction in migraineurs (23).

Such results support the theory that migraineurs have higher oxidant levels, but mitochondrial dysfunction has never been in tension-type headache, that is indicate the lower levels of oxidative stress seen in these groups. Beside mitochondrial dysfunction in migraine 
patients, the activity of free radicals in migraine can be associated with NO, which markedly dilates cerebral vessels, is a nociceptive neurotransmitter and as one of the major factors regulating cerebral flow plays a key role in the trigeminovascular mechanism of migraine. Markedly, elevated levels of NO and its metabolites in blood and platelets between seizures (24) seem to confirm the involvement of this molecule in the pathogenic chain peroxides, which open calcium-dependent potassium canals by distending brain arteries are another factor of brain flow auto regulation cooperating with NO.

Increased blood flow through cerebral cortex leads to stimulation of the periaquedutal grey matter. In such situation, brain structures may be potentially exposed to damage by free radicals due to repeated episodes of hyperoxia during migraine seizures .Migraine suffers can be more vulnerable to toxic effects of free radicals. The mechanism of one of the drugs used in the prevention of migraine, flunarizine, is based on its free radical scavenging action which reduces oxidative stress (25)

\section{Conclusion}

Results of recent study confirm the disorder in brain energy metabolism with disturbances of lipid peroxidation in migraine, this indicates that the increase in the lipid peroxidation, suggesting that anti-migraine treatment may also modify the oxidant-antioxidant balance; and free radical scavengers may provide a potential molecular basis for prophylactic anti-migraine therapy.

\section{$\underline{\text { Figures \&Tables }}$}

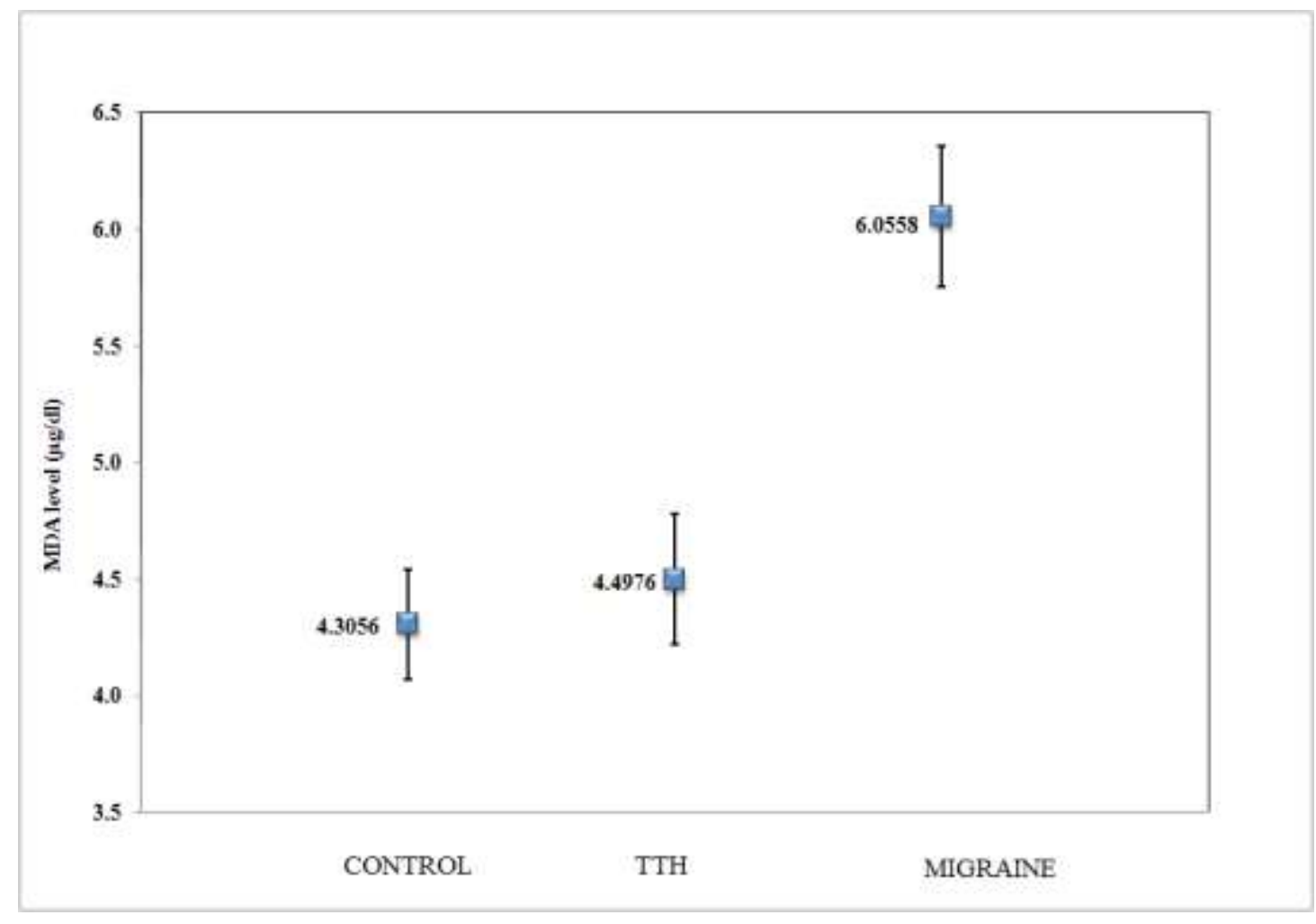

Figure (1): Plasma MDA levels (Mean \pm SE) for the three studied groups. 


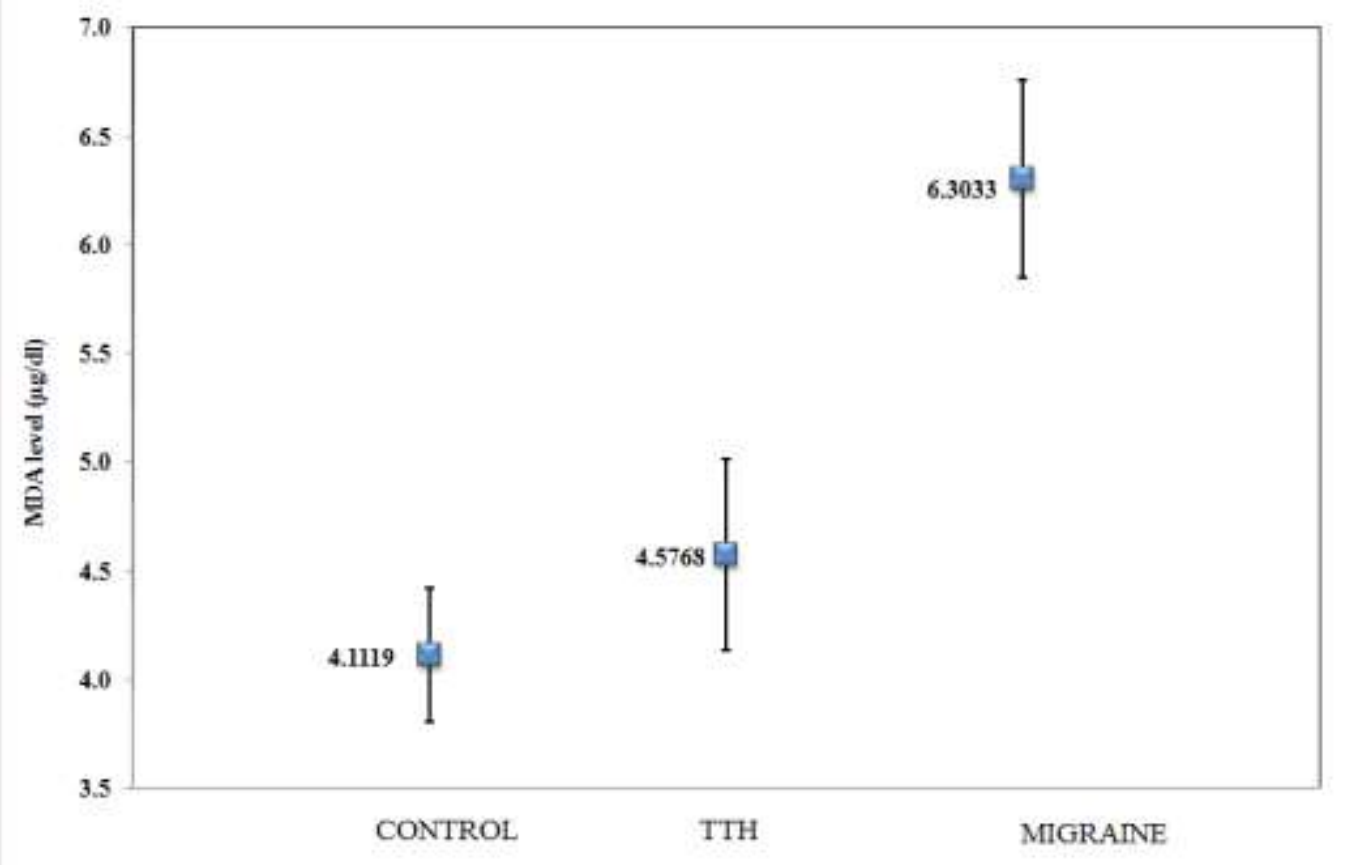

Figure (2): Plasma MDA levels (Mean \pm SE) for the three males'subgroups

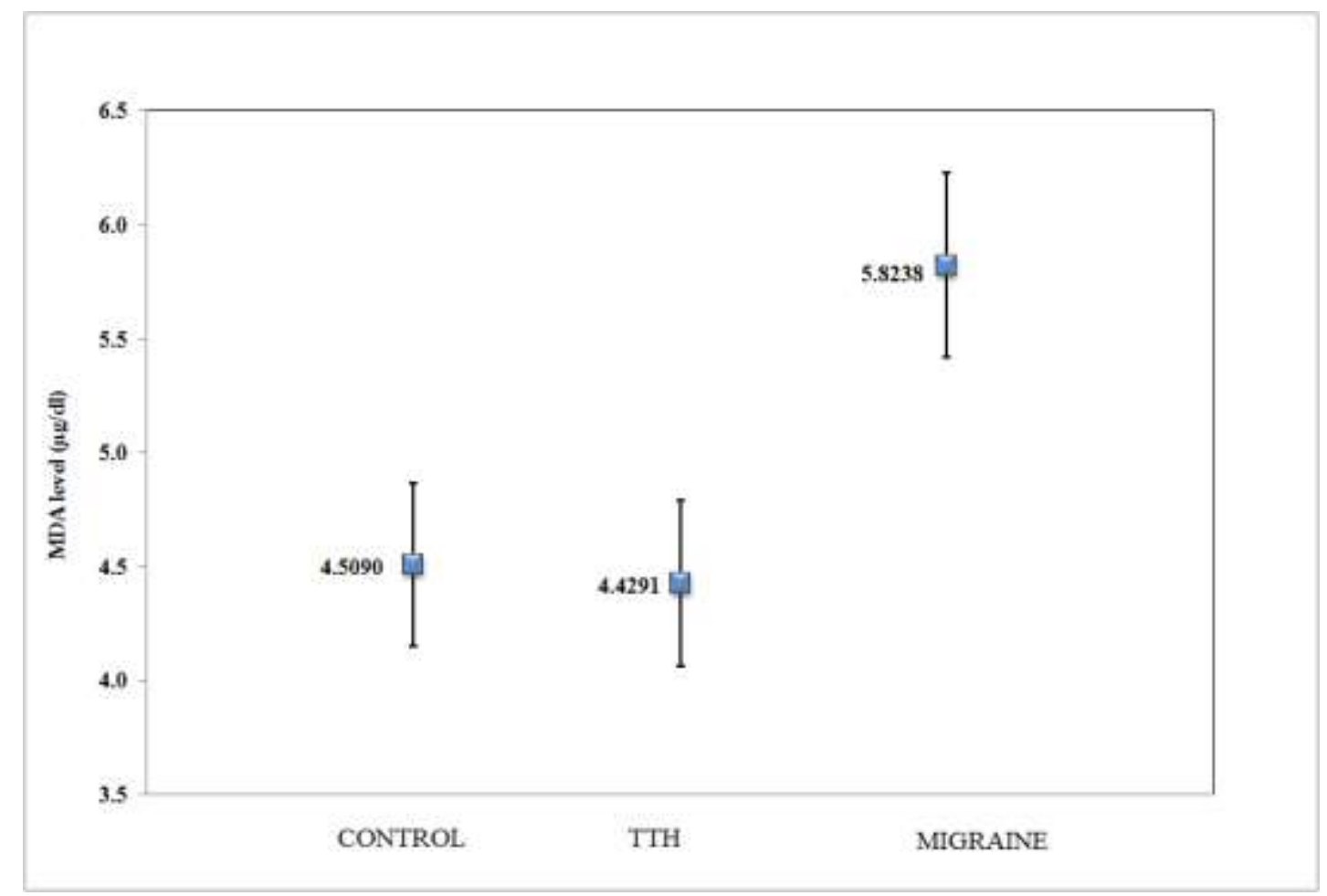

Figure (3): Plasma MDA levels (Mean $\pm \mathrm{SE}$ ) for the three females' subgroups. 
Table (1): Age descriptions for patient divided according to gender

\begin{tabular}{|c|c|c|c|c|c|c|}
\hline Group & Gender & Number & AGE (mean) & 土AGE (SD) & AGE (min) & AGE (max) \\
\hline \multirow{2}{*}{ Control } & Males & $20(48.78 \%)$ & 31.85 & 9.045 & 17 & 48 \\
\cline { 2 - 7 } & Females & $21(51.22 \%)$ & 32.14 & 9.334 & 18 & 50 \\
\hline \multirow{2}{*}{ TTH } & Males & $22(53.66 \%)$ & 32.64 & 9.594 & 18 & 55 \\
\cline { 2 - 7 } & Females & $19(46.34 \%)$ & 32.11 & 7.745 & 19 & 51 \\
\hline \multirow{2}{*}{ Migraine } & Males & $16(51.61 \%)$ & 33.63 & 7.830 & 17 & 45 \\
\cline { 2 - 7 } & Females & $15(48.39 \%)$ & 35.60 & 9.379 & 20 & 53 \\
\hline
\end{tabular}

Table (2): Descriptive table of MDA level for the main three groups included:

\begin{tabular}{|c|c|c|c|c|c|c|}
\hline group & $\mathbf{N}$ & $\begin{array}{c}\text { Mean } \\
(\boldsymbol{\mu g} / \mathbf{d} \mathbf{)})\end{array}$ & $\mathbf{\pm}$ Std. Deviation & $\mathbf{\pm}$ Std. Error & Minimum & Maximum \\
\hline CONTROL & 41 & 4.3056 & \pm 1.49448 & 0.23340 & 1.30 & 8.22 \\
\hline TTH & 41 & 4.4976 & \pm 1.78857 & 0.27933 & 1.74 & 8.06 \\
\hline MIGRAINE & 31 & 6.0558 & \pm 1.68454 & 0.30255 & 3.34 & 9.23 \\
\hline
\end{tabular}

Table (3): Males' subgroups statistical descriptions:

\begin{tabular}{|c|c|c|c|c|c|c|}
\hline group & $\mathbf{N}$ & $\begin{array}{c}\text { Mean } \\
(\boldsymbol{\mu g} / \mathbf{d l})\end{array}$ & $\mathbf{\pm S t d . ~ D e v i a t i o n ~}$ & $\mathbf{\pm S t d . ~ E r r o r ~}$ & Minimum & Maximum \\
\hline CONTROL & 20 & 4.509 & \pm 1.5887 & 0.3552 & 1.50 & 8.12 \\
\hline TTH & 22 & 4.429 & \pm 1.7141 & 0.3654 & 2.19 & 7.98 \\
\hline MIGRAINE & 16 & 5.824 & \pm 1.6248 & 0.4062 & 3.34 & 8.83 \\
\hline
\end{tabular}

Table (4): Females' subgroups statistical descriptions:

\begin{tabular}{|c|c|c|c|c|c|c|}
\hline group & $\mathbf{N}$ & $\begin{array}{c}\text { Mean } \\
(\boldsymbol{\mu g} / \mathbf{d} \mathbf{l})\end{array}$ & $\begin{array}{c}\mathbf{\pm} \text { Std. } \\
\text { Deviation }\end{array}$ & $\mathbf{\pm S t d . ~ E r r o r}$ & Minimum & Maximum \\
\hline CONTROL & 21 & 4.112 & \pm 1.410 & 0.3077 & 1.30 & 8.22 \\
\hline TTH & 19 & 4.577 & \pm 1.915 & 0.4394 & 1.74 & 8.06 \\
\hline MIGRAINE & 15 & 4.870 & \pm 1.896 & 0.2556 & 3.72 & 9.23 \\
\hline
\end{tabular}


Table (5): MDA values as measured according to age in CONTROL

\begin{tabular}{|c|c|c|c|c|c|}
\hline \multirow[t]{2}{*}{ Sex } & \multirow[t]{2}{*}{ Age (year) } & \multirow{2}{*}{$\underset{\mathbf{n}}{\text { Number }}$} & \multirow{2}{*}{$\begin{array}{l}\text { Mean MDA } \\
\pm \mathrm{SD}(\mu \mathrm{g} / \mathrm{dl})\end{array}$} & \multicolumn{2}{|c|}{$\begin{array}{l}95 \% \text { confidence interval } \\
\text { for mean }\end{array}$} \\
\hline & & & & Upper & Lower \\
\hline $\mathrm{M}$ & $15-27$ & 7 & $3.85 \pm 1.36$ & 2.59 & 5.10 \\
\hline$M$ & $28-40$ & 10 & $4.61 \pm 1.25$ & 3.72 & 5.51 \\
\hline $\mathrm{M}$ & $41-53$ & 3 & $4.51 \pm 1.59$ & 1.14 & 12.58 \\
\hline $\mathrm{F}$ & $15-27$ & 7 & $3.70 \pm 0.85$ & 2.91 & 4.49 \\
\hline $\mathrm{F}$ & $28-40$ & 10 & $4.15 \pm 1.30$ & 3.216 & 5.08 \\
\hline $\mathrm{F}$ & $41-53$ & 4 & $4.74 \pm 2.40$ & 0.91 & 8.57 \\
\hline
\end{tabular}

Table (6): MDA values as measured according to age in TTH group

\begin{tabular}{|c|c|c|c|c|c|}
\hline \multirow{2}{*}{ Sex } & \multirow{2}{*}{ Age (year) } & \multirow{2}{*}{$\begin{array}{c}\text { Number } \\
\mathbf{n}\end{array}$} & \multirow{2}{*}{$\begin{array}{c}\text { Mean MDA } \\
\mathbf{\pm S D}(\boldsymbol{\mu g} / \mathbf{d l})\end{array}$} & \multicolumn{2}{|c|}{$\begin{array}{c}\text { 95\% confidence interval } \\
\text { for mean }\end{array}$} \\
\cline { 5 - 6 } & & & & Upper & Lower \\
\hline $\mathrm{M}$ & $15-27$ & 8 & $4.37 \pm 1.90$ & 2.80 & 5.95 \\
\hline $\mathrm{M}$ & $28-40$ & 9 & $4.28 \pm 1.84$ & 2.87 & 5.70 \\
\hline $\mathrm{M}$ & $41-53$ & 5 & $4.70 \pm 1.46$ & 2.97 & 6.61 \\
\hline $\mathrm{F}$ & $15-27$ & 5 & $3.41 \pm 1.61$ & 1.42 & 5.41 \\
\hline $\mathrm{F}$ & $28-40$ & 11 & $4.58 \pm 1.79$ & 3.38 & 5.78 \\
\hline $\mathrm{F}$ & $41-53$ & 3 & $6.51 \pm 1.68$ & 2.33 & 10.69 \\
\hline
\end{tabular}

Table (7): MDA values as measured according to age in MIGRAINE

\begin{tabular}{|c|c|c|c|c|c|}
\hline \multirow{2}{*}{ Sex } & \multirow{2}{*}{ Age (year) } & \multirow{2}{*}{$\begin{array}{l}\text { Number } \\
\mathbf{n}\end{array}$} & \multirow{2}{*}{$\begin{array}{c}\text { Mean } \\
\text { MDA } \\
\pm \mathrm{SD} \\
(\mu \mathrm{g} / \mathrm{dl})\end{array}$} & \multicolumn{2}{|c|}{$\begin{array}{l}\text { 95\% confidence interval for } \\
\text { mean }\end{array}$} \\
\hline & & & & Upper & Lower \\
\hline $\mathrm{M}$ & $15-27$ & 4 & $5.12 \pm 1.68$ & 2.44 & 7.80 \\
\hline $\mathrm{M}$ & $28-40$ & 8 & $5.73 \pm 1.66$ & 4.34 & 7.12 \\
\hline $\mathrm{M}$ & $41-53$ & 4 & $6.71 \pm 1.47$ & 4.36 & 9.06 \\
\hline $\mathrm{F}$ & $15-27$ & 3 & $4.33 \pm 0.61$ & 2.83 & 5.83 \\
\hline \multirow[t]{2}{*}{$\mathrm{F}$} & $28-40$ & 8 & $6.76 \pm 1.59$ & 5.43 & 8.09 \\
\hline & $41-53$ & 4 & $6.87 \pm 1.88$ & 3.88 & 9.87 \\
\hline
\end{tabular}




\section{References}

1.Leszek Bckwski: Some aspects of the pathophysiology of migraine in children and adolescents: Artykul Readakcyjny, 2010; 19:21-25.

2.Welch KM, Levine SR, D Andrea G, Schultz LR, Helpersn JA, Preliminary observation on brain energy metabolism in migraine studies by in vivo phosphorus NMR spectroscopy. Neurology 1989;39:538-41

3.Headache Classification Committee of International Headache Society .Classification and diagnostic criteria for headache disorders, cranial neuralgias and facial pain. Cephalalgia 1988; (suppl 7) 196.

4.Olesen J, Peer TF. Hansen, K .Michael AW. The Headache Philadelphia: LippincottWilliams andWilkins, 2000; 227-33.

5.Frankel EN: Recent advances in lipid oxidation J.Sci Food Aqric1991, 54; 495- 511.

6.McCord JM: Human disease, free radicals, and the oxidant/antioxidant balance. Clin Biochem, 1993, 26; 351-357.

7.Tuszkiewicz-Misztal E, Opoka- Winiarska V, Postêpski J: Significance of dietary antioxidants for child proper development and health (Polish). Pediatr Pol, 2000, 75; 359-366.

8.Artemowicz B, Sobaniec W: Investigation of lipid peroxidation and antioxidant enzymes activity in the serum of epileptic children (Polish). Epileptologia, 2001, 9; 167-178.

9.Sobaniec W, Kuak W, Boækowski L, OE migielska-KuziaJ, Sobaniec-Lotowska M, Soowiej E, Sobaniec H, Artemowicz B: Studies of damage processes of nervous and possibilities of neuro protection (Polish).Przegl Lek, 2001, 58; 41-47.

10. Sobaniec W, Soowiej E, Kuak W, Boækowski L OEmigielska-Kuzia J, Artemowicz B: Evaluation of the influence of antiepileptic therapy on antioxidant enzyme activity and lipid peroxidation in erythrocytes of children with epilepsy. Child Neurol, 2006, $21 ; 558-562$.

11. Shah SV and Walker PD: Evidence suggesting a role for hydroxyl radical in glycerol induced acute renal failure Am.J.Physiol. Renal fluid electrolyte physiol. 1988, 24; 438-443.

12. Mahboob M, Rahman MF, Grover P: Serum lipid peroxidation and antioxidant enzyme level in male and female diabetic patients, Singapore Med .J.2005; 46(7):322.

13. Luqman A.Olayaki, Salihu M.Ajao, Ggfar A .A Jimoh, I.T. Aremu and Ayodele O .Soladoye: Effect of vitamin $\mathrm{C}$ on malondialdehyde (MDA) in pregnant Nigerian women .Journal of Basic and Applied Sciences .2008, 2; 105-108.

14. Glaubic-Latka M, Latka D, Bury W, Pierzcha ${ }^{3} a$ $\mathrm{K}$ : Current opinions on migraine pathophysiology. (Polish)Neurol Neurochir Pol, 2004, 38; 307-315.

15. Cincarelli I, Tozzi-Ciancarelli MG, Di Massimo C,Marini C, Carolei A: Urinary nitric oxide metabolites and lipid peroxidation by-products in migraine.Cephalalgia, 2003, 23;39-42.

16. Shimomura T, Kowa H, Nakano T, Kitano A, MarukawaH, Urakami K, Takahashi K: Platelet superoxide dismutase in migraine and tension-type headache. Cephalalgia 1994, 14;215-218 
17. Tozzi-Ciancarelli MG, DeMatteis G, DiMassimo C,Marini C, Ciancarelli I, Carolei A: Oxidative stress and platelet responsiveness in migraine. Cephalalgia, 1997, 17; 580-584.

18. Nielsen F, Mikkelsen BB, Nielsen JB, Andersen HR, Grandjean P: Plasma malondialdehyde as biomarker for oxidative stress: reference interval and effects of life-style factors. Clin Chem, 1997, 43; 1209-1214.

19. Diaz J, Serrano E, Acosta F, Carbonell LF: Referenceintervals for four biochemistry analytes in plasma for evaluating oxidative stress and lipid peroxidation in human plasma. Clin Chem, 1998, 44; 2215-2217.

20. Moskowitz MA, Buzzi MG, Sakas DE, Linnik MD: Pain mechanisms underlying vascular headaches.Progress Report 1989. Rev Neurol, 1989, 145, 181-193.

21. Chayasirisobhon S: Use of a pine bark extract and antioxidant vitamin combination product as therapy for migraine in patient's refractory to pharmacologic medication.Headache, 2006, 46, 788-793.

22. Kabbouce MA,Powers SW, Vockell AL,Lecates SL,Hershey AD.Carnitine palmityltransferase II(CPT2) deficiency and migraine headace :Two case reports.Headache. $2003 ; 43: 490-5$

23. Okada H, Araga S, Takeshima T, Nakashima K. Plasma lactic acid and pyruvic acid levels in migraine and tension-type headache. Headache. 1998; 38:39-42.

24. D'Amico D, Ferraris A, Leone M, Catania A, Carlin A, Grazzi I, Bussone G: Increased plasma nitrites in migraine and cluster headache patients in interictal period: basal hyperactivity of L-arginine
NO pathway? Cephalalgia, 2002, 22, 3336.

25. Leszek B., Wojciech S., Wojiciech K., and Joanna S.: Serum and intarerythrocyte antioxidant enzymes and lipid peroxides in children with migraine .Pharmacological Reports 2008; 60,542-548. 